The Idea of the Canterbury Tales 


\section{The Idea of the}

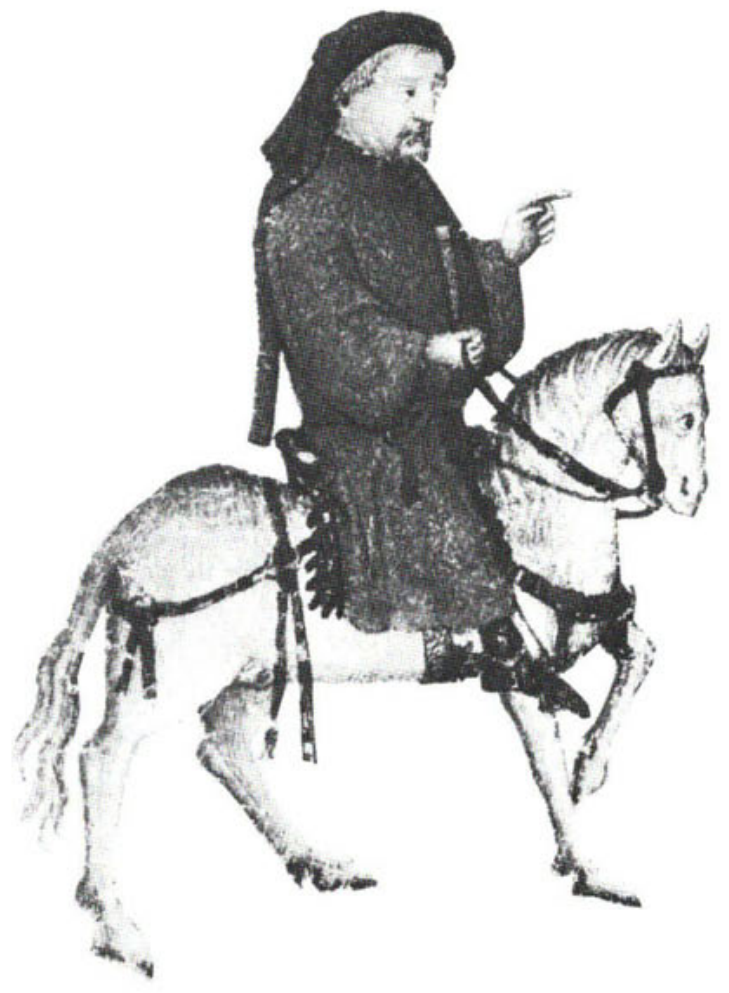




\section{Ganterburu Tales}

\section{Donald R. Howard}

UNIVERSITY OF CALIFORNIA PRESS

BERKELEY LOS ANGELES LONDON 
University of California Press

Berkeley and Los Angeles, California

University of California Press, Ltd., London, England

Copyright 1976 by The Regents of the University of California

First Paperback Edition, 1978

ISBN 0-520-03492-9 (paperback)

0-520-02816-3 (clothbound)

Library of Congress Catalog Card Number: 74-81433

Printed in the United States of America

Designed by Dave Comstock 
TO THE MEMORY OF

Francis Lee Utley

$1907-1974$ 
